\title{
ИДЕИ ГОСУДАРСТВЕННОГО ЕДИНСТВА В ПОЛИТИКО-ПРАВОВЫХ ВОЗЗРЕНИЯХ А. С. ПУШКИНА
}

\begin{abstract}
Аннотация: Предметом исследования являются идеи государственного единства, выраженные в творчестве великого русского писателя А. С. Пушкина. Цели работы заключаются в анализе художественных, научно-исторических работ и источников личного происхождения (переписка) для определения позиций писателя относительно проблем государственного единства и противодействия центробежным тенденциям в истории России и современной Пушкину Российской империи. Особое внимание уделяется таким источниками, как стихотворения "Клеветникам России", "Бородинская годовщина", поэма "Полтава", исторические сочинения "Заметки по русской истории", "Очерк истории Украинь", а также переписка с П. А. Вяземским. В ходе работы использованы исторический и сравнительный методы исследования, системный анализ, а также контекстологический анализ текста. Научная новизна проведенного исследования заключается в постановке проблемы и привлечении материалов, ранее практически не задействованных для нужд истории учений о праве и государстве. Проведенная работа позволяет заключить, что А. С. Пушкин в различных по жанру и назначению произведениях последовательно занимал чёткую позииию по вопросу необходимости обеспечения государственного единства России.
\end{abstract}

Ключевые слова: А. С. Пушкин, государственное единство, территориальная иелостность, российская государственность, суверенитет, Польша, Украина, иентробежные тенденции, сепаратизм, государственное преступление.

Abstract: The subject of this research is the ideas of national unity expressed in the work of the great Russian poet Alexander Sergeyevich Pushkin. The goal of this work is to analyze the creative and scientific-historical works and personal sources (correspondence) in order to determine the positions of the writer with regards to the issues of national unity and counteraction of the centrifugal trends within the history of Russia, and the Russian Empire contemporary to Pushkin. A special attention is given to sources such as the poems "To the Slanderers of Russia", "The Anniversary of Borodino", "Poltava", historical essays "Notes on Eighteen-century Russian History", "Essays on the History of Ukraine", as well as his correspondence with Pyotr Vyazemsky. The scientific novelty of this research consists in the presentation of the problem and the use of materials that virtually have not previously been implemented in the research on the history of education on law and state. This work allowed making a conclusion that Alexander Pushkin in his works of various genre has systematically established a precise position on the issue of the need to ensure national unity in Russia.

Keywords: Centrifugal tendencies, Ukraine, Poland, sovereignty, Russian statehood, territorial integrity, state unity, Pushkin, separatism, state crime.

ля многих стран современного мира со всей актуальностью встает вопрос сохранения государственного единства. Данная проблема возникает в государствах независимо от их принадлежности к тому или иному континенту, главенствующего экономического уклада или политического режима. В юридической литературе государственное единство понимается как отказ от каких-либо проявлений сепаратизма, то есть такой политики в отдельных частях государства, которая не учитывает интересов всего государства, противопоставляя им местные интере- сы [5, с. 144]. Также отмечается, что государственное единство предполагает весьма значительный объем и высокий уровень согласованных позиций, интересов и отношений между институтами государственности, взаимосвязанных с политической и правовой системами, а также с гражданским обществом на основе взаимодействия в разрешении конкретных проблем общественного развития, что обеспечивает устойчивую структуру власти и властных отношений в государстве, его территориальную целостность [7, с. 13]. Как можно заметить, вопрос территориальной целостности явля- 
DOI: $10.7256 / 1811-9018.2015 .9 .14629$

При цитировании этой статьи сноска на доі обязательна

\section{Право и политика 9 (189) • 2015}

ется ключевым в проблеме государственного единства, в этой связи данные термины зачастую используются в одном и том же контексте.

Россия в силу своего многонационального, поликонфессионального и мультикультурного характера практически на всех этапах своего исторического развития вынуждена была решать задачу сохранения своего единства. В этой связи отечественными государствоведами, писателями и общественными деятелями накоплен значительный теоретический и практический опыт. Исследования свидетельствуют, что произведения художественной литературы и источники личного происхождения могут представлять значительный интерес для историков государства и права $[1,3,4,6,8,19]$. В рамках данной статьи попытаемся обобщить и проанализировать политико-правовые воззрения на вопросы государственного единства величайшего русского писателя Александра Сергеевича Пушкина (1799-1837).

Проблема государственного единства нередко затрагивалась Пушкиным в его научных произведениях по истории России средних веков. Он обращает внимание на феодальную раздробленность как на явление, негативно воздействовавшее на русскую государственность: «... Россия не окрепла и не развилась во время княжеских драк (как энергически называл Карамзин удельные междоусобия), на, напротив, ослабла и сделалась легкою добычею татар...» [10, с. 148]. Исследователь отмечал изначально присутствовавшее на Руси единство, традиционное для отечественных политических отношений: «...князья в своих уделах являлись представителями государя, которым было поручено подавлять возмущения и отражать нападения врагов. Это, как мы видим, вовсе не была < ..> система, основанная на независимости отдельных лии (выделено нами - Ф.С.) и на равном праве их участия в добыче» [13, с. 111]; «Удельные князья зависели от единого великого князя...» [11, с. 109].

В письме П.А.Вяземскому от 1 июня 1831 г. поэт высказывается по поводу противодействия правительственных войск польским повстанцам, выражая решительную поддержку вооруженному подавлению мятежа: «... всё-таки их надобно задушить, и наша медлительность мучительна» [14, с. 244]. Он придерживается позиции безусловного признания Царства Польского частью России, утверждая: «Для нас мятеж Польши есть дело семейственное, старинная, наследственная распря. ..» [14, c. 244]. Эта мысль в поэтической форме была выражена в стихотворении «Клеветникам России»:

«Оставьте: это спор славян между собою,

Домашний, старый спор, уж взвешенный судьбою» $[12$, c. 66$]$.
Проблема целостности России в связи с восстанием 1831 года не ограничивалась только пределами Царства Польского. Дело в том, что польские сепаратисты выступали также с требованием отделения от России и присоединения к Польше территории Украины вплоть до Днепра. Такие политические требования озвучены А. С. Пушкиным с явной негативной оценкой в стихотворении «Бородинская годовщина»:

«Куда отдвинем строй твердынь?

За Буг, до Ворсклы, до Лимана?

За кем останется Волынь?

За кем наследие Богдана?

Признав мятежные права,

От нас отторгнется ль Литва?

Наш Киев дряхлый, златоглавый,

Сей пращур русских городов,

Сроднит ли с буйною Варшавой

Святыню всех своих гробов?» [9, с. 69].

Польское восстание недвусмысленно характеризуется Пушкиным как бунт, то есть государственное преступление, в этой связи поэтом выражено одобрение пресечению этого опасного для государственной целостности процесса: «И бунт раздавленный умолк» [9, с. 69].

Государственное единство Российской империи, безусловно, позиционируется как одна из высших политико-правовых ценностей в данном патетическом отрывке:

«Сильна ли Русь? Война, и мор,

И бунт, и внешних бурь напор

Ее, беснуясь, потрясали -

Смотрите ж: всё стоит она!

А вкруг ее волненья пали -

И Польши участь решена...» [9, с. 70].

Поскольку защита собственной целостности и противодействие сепаратистским выступлениям есть внутреннее дело России, то, по мнению поэта, «...выгода почти всех правительств держаться в сем случае правила non-intervertion (невмешательства (фр.) - прим. автора)» [14, с. 244]. То есть Пушкин в данном случае, на наш взгляд, заявляет об обеспечении территориальной целостности как проявлении суверенитета Российской империи.

Следует отметить, что Пушкин занимает по поводу вопроса о возможности государственного самооопределении Польши отчетливо консервативную позицию. По данной проблеме он расходится со многими декабристами, политико-правовые позиции которых в целом были близки поэту $[18$, с. 23$]$. «Польский вопрос», то есть в данном случае проблема нейтрализации сепаратистских выступлений в Царстве Польском и сохранения Польши, а также украинских и литовских земель в со- 
DOI: $10.7256 / 1811-9018.2015 .9 .14629$

При цитировании этой статьи сноска на dоі обязательна

Правовая и политическая мысль

ставе Российской империи, неизменно заботит поэта и не раз развивается в его письмах [16, с. $279 ; 15$, с. 244].

Проблема сепаратизма и противодействия ему, в том числе правовыми средствами, затронута и развита в поэме «Полтава», значительная часть которой посвящена предательству гетмана Мазепы. В современной юридической литературе под сепаратизмом понимается стремление отделиться, обособиться; движение за отделение части государства и создание нового государственного образования или за предоставление части страны автономии [2, с. 544]. Мазепа в поэме, таким образом, характеризует свое движение как сепаратистское в самом агрессивном смысле:

«Без милой вольности и славы

Склоняли долго мы главы

Под покровительством Варшавы,

Под самовластием Москвы.

Но независимой державой

Украйне быть давно пора:

И знамя вольности кровавой

Я подымаю на Петра» [17, с. 206].

Действия самого Мазепы и его сторонников характеризуются самыми нелестными эпитетами, свидетельствующими о её оценке как преступной и аморальной автором поэмы: «мятежный крик» [17, с. 194], «преступны виды» [17, с. 195], «умысел ужасный» [17, с. 196], «повсюду тайно сеют яд» [17, с. 200], «врагу России самому» [17, с. 201], «изменник русского царя» [17, с. 224], «злодей», «Иуда» [17, с. 229] и другими.

Единство же России и Украины, по выраженной в поэме мысли, основано, прежде всего, на традициях и праве. Так, по выражению поэта, сторонники отделения Украины действуют,

«Забыв отчизны давний плен,

Богдана счастливые споры,

Святые брани, договоры (выделено нами - Ф.С.) $[17$, c. 195$] \gg$.
Мазепа, как известно, избежал юридической ответственности за государственное преступление, которой, по мнению поэта, заслуживал: «Зачем изменник не на плахе?» [17, с. 229]. Вместе с тем за неимением Мазепы физически, церковь наказывает его по-своему («Гремит анафема в соборах» [17, с. 221]), а государство осуждает его символически. Пушкин приводит в сносках к поэме следующую меру, имевшую, по всей видимости, символически-воспитательный и устрашающий для возможных последователей Мазепы характер: «...9-го дня персону (куклу)...изменника Мазепы вынесли и, сняв кавалерию (которая на ту персону была надета с бантом) оную персону бросили в палачевские руки, которую палач, взяв и прицепя за веревку, тащил по улице и по площади даже до виселицы, и потом повесили» [17, с. 221]. В целом мероприятия Петра I по ликвидации мятежа и нейтрализации сепаратистского движения в целом положительно оцениваются поэтом: «Сильные меры, принятые Петром с обыкновенной его быстротой и энергией, удержали Украину в повиновении» [17, с. 221].

Таким образом, А. С. Пушкин неоднократно высказывал мысли в поддержку государственного единства России и целостности её границ. Произведения А. С. Пушкина - это, конечно, прежде всего, художественные либо исторические научные произведения, а не юридические трактаты, поэтому в них нет специальных рассуждений по вопросам права и государства. Вместе с тем, ряд замечаний поэта, позиции, высказываемые им по поводу важных исторических событий прошлых и современных ему эпох, эмоциональная окраска образов героев произведений, свидетельствуют о приверженности А. С. Пушкина идеям государственного единства. Позиция Пушкина по данному вопросу тем более интересна для ученых-юристов, что поэт, помимо прочего, имел юридическое образование, которое получил в Царскосельском лицее.

\section{Библиография:}

1. Бабкин В. Д. М. Е. Салтыков - Щедрин - критик военно-бюрократической машины эксплуататорского государства (к 150-летию со дня рождения) // Советское государство и право. - 1977. - №1. - С. 107 - 114.

2. Большой юридический словарь / Под ред. А. Я. Сухарева, В. Е. Крутских. - 2-е изд., перераб. и доп. - М.: ИНФРА-М, 2000. - 704 c.

3. Кодан С. В. «Записки из мертвого дома» Ф. М. Достоевского как документально-художественный источник изучения истории государства и права // Genesis: исторические исследования. - 2014. - №4. - С. 120 - 140.

4. Кодан С. В. Источники личного происхождения как носители историко-юридической информации // Политика и общество. - 2014. - №3. - С. $322-335$.

5. Конституционное право: энциклопедический словарь / отв. ред. С. А. Авакьян. - М.: НОРМА, 2001. - 688 с.

6. Куприц Н. Я. Критика царизма и его государственного аппарата в произведениях Льва Толстого (По страницам «Войны и мира», «Анны Карениной», «Воскресения») // Советское государство и право. - 1978. - №9. - С. 97 - 105.

7. Левакин И. В. Государственное единство России: теоретико-правовое исследование: дис....д.ю.н. - М., 2003. - 304 с. 


\section{Право и политика 9 (189) 2015}

8. Ландау Б. Защита родины и вопросы права в «Слове о полку Игореве» // Советское государство. - 1938. - №4. - С. 130 - 133.

9. Пушкин А. С. Бородинская годовщина // Пушкин А. С. Собрание сочинений: В 15 т. Т. 4: Стихотворения 1830 - 1836 ; Коллективное. Приписываемое Пушкину; Из ранних редакций; Песни и сказки, собранные и записанные Пушкиным .- М.: TEPPA, 1998. - С. $68-70$.

10. Пушкин А. С. Второй том «Истории русского народа» Полевого // Пушкин А. С. Собрание сочинений: В 15 т. Т. 9: Отрывки и наброски; Планы ненаписанных произведений; Статьи и заметки; Из ранних редакций. - М.: ТЕРРА, 1998. - С. 146 - 149.

11. Пушкин А. С. Заметки по русской истории // Пушкин А. С. Собрание сочинений: В 15 т. Т. 10: Автобиографическая проза; Историческая проза; Статьи и заметки; Наброски, записи, конспекты, планы; Заметки на полях; Приписываемое Пушкину; Из ранних редакций. - М.: ТЕРРА, 1998. - С. 111 - 112.

12. Пушкин А. С. Клеветникам России // Пушкин А. С. Собрание сочинений: В 15 т. Т. 4: Стихотворения 1830 - 1836 ; Коллективное. Приписываемое Пушкину; Из ранних редакций; Песни и сказки, собранные и записанные Пушкиным .- М.: ТЕPPA, 1998. - С. $66-67$.

13. Пушкин А. С. Очерк истории Украины // Пушкин А. С. Собрание сочинений: В 15 т. Т. 10: Автобиографическая проза; Историческая проза; Статьи и заметки; Наброски, записи, конспекты, планы; Заметки на полях; Приписываемое Пушкину; Из ранних редакций. - М.: ТЕРРА, 1998. - С. $105-110$.

14. Пушкин А. С. Письмо П. А. Вяземскому от 1 июня 1831 года // Пушкин А. С. Собрание сочинений: В 15 т. Т. 14 : Письма. 1828 - 1832. - M.: TEPPA, 1998. - С. $244-245$.

15. Пушкин А. С. Письмо П. А. Вяземскому от 14 августа 1831 года // Пушкин А.С. Собрание сочинений: В 15 т. Т. $14:$ Письма. 1828 - 1832. - M.: TEPPA, 1998. - C. $291-292$.

16. Пушкин А. С. Письмо П. В. Нащокину от 29 июля 1831 года // Пушкин А.С. Собрание сочинений: В 15 т. Т. $14:$ Письма. 1828 - 1832. - M.: TEPPA, 1998. - C. 279.

17. Пушкин А. С. Полтава // Пушкин А. С. Собрание сочинений: В 15 т. Т. 5: Поэмы; Из ранних редакций; Песни и сказки, собранные и записанные Пушкиным. - М.: ТЕРРА, 1998. - С. 188 - 234.

18. Сосенков Ф. С. Вопросы обеспечения территориальной целостности России в политико-правовых воззрениях декабристов // Вестник Волжской государственной академии водного транспорта. - 2014. Выпуск 38. - С. 15 - 28.

19. Хайруллин В. И. Справедливое общество или «утопизм» Достоевского // Государство и право. - 2004. - №8. - С. 100 - 105.

\section{References (transliterated):}

1. Babkin V. D. M. E. Saltykov - Shchedrin - kritik voenno-byurokraticheskoi mashiny ekspluatatorskogo gosudarstva (k 150-letiyu so dnya rozhdeniya) // Sovetskoe gosudarstvo i pravo. - 1977. - №1. - S. 107 - 114.

2. Kodan S. V. «Zapiski iz mertvogo doma» F. M. Dostoevskogo kak dokumental'no-khudozhestvennyi istochnik izucheniya istorii gosudarstva i prava // Genesis: istoricheskie issledovaniya. - 2014. - №4. - S. 120 - 140.

3. Kodan S. V. Istochniki lichnogo proiskhozhdeniya kak nositeli istoriko-yuridicheskoi informatsii // Politika i obshchestvo. 2014. - №3. - S. 322 - 335.

4. Kuprits N. Ya. Kritika tsarizma i ego gosudarstvennogo apparata v proizvedeniyakh L’va Tolstogo (Po stranitsam «Voiny i mira», «Anny Kareninoi», «Voskreseniya») // Sovetskoe gosudarstvo i pravo. - 1978. - №9. - S. 97 - 105.

5. Levakin I. V. Gosudarstvennoe edinstvo Rossii: teoretiko-pravovoe issledovanie: dis....d.yu.n. - M., 2003. - 304 s.

6. Landau B. Zashchita rodiny i voprosy prava v «Slove o polku Igoreve» // Sovetskoe gosudarstvo. - 1938. - №4. - S. 130 - 133.

7. Pushkin A. S. Borodinskaya godovshchina // Pushkin A. S. Sobranie sochinenii: V 15 t. T. 4: Stikhotvoreniya 1830 - 1836 ; Kollektivnoe. Pripisyvaemoe Pushkinu; Iz rannikh redaktsii; Pesni i skazki, sobrannye i zapisannye Pushkinym . - M.: TERRA, 1998. - S. $68-70$.

8. Pushkin A. S. Vtoroi tom «Istorii russkogo naroda» Polevogo// Pushkin A. S. Sobranie sochinenii: V 15 t. T. 9: Otryvki i nabroski; Plany nenapisannykh proizvedenii; Stat'i i zametki; Iz rannikh redaktsii. - M.: TERRA, 1998. - S. 146 - 149.

9. Pushkin A. S. Zametki po russkoi istorii // Pushkin A. S. Sobranie sochinenii: V 15 t. T. 10: Avtobiograficheskaya proza; Istoricheskaya proza; Stat'i i zametki; Nabroski, zapisi, konspekty, plany; Zametki na polyakh; Pripisyvaemoe Pushkinu; Iz rannikh redaktsii. - M.: TERRA, 1998. - S. $111-112$.

10. Pushkin A. S. Klevetnikam Rossii // Pushkin A. S. Sobranie sochinenii: V 15 t. T. 4: Stikhotvoreniya 1830 - 1836 ; Kollektivnoe. Pripisyvaemoe Pushkinu; Iz rannikh redaktsii; Pesni i skazki, sobrannye i zapisannye Pushkinym . - M.: TERRA, 1998. - S. $66-67$.

11. Pushkin A. S. Ocherk istorii Ukrainy // Pushkin A. S. Sobranie sochinenii: V 15 t. T. 10: Avtobiograficheskaya proza; Istoricheskaya proza; Stat'i i zametki; Nabroski, zapisi, konspekty, plany; Zametki na polyakh; Pripisyvaemoe Pushkinu; Iz rannikh redaktsii. - M.: TERRA, 1998. - S. $105-110$.

12. Pushkin A. S. Pis'mo P. A. Vyazemskomu ot 1 iyunya 1831 goda // Pushkin A. S. Sobranie sochinenii: V 15 t. T. 14 : Pis'ma. 1828 - 1832. - M.: TERRA, 1998. - S. $244-245$.

13. Pushkin A. S. Pis'mo P. A. Vyazemskomu ot 14 avgusta 1831 goda // Pushkin A.S. Sobranie sochinenii: V 15 t. T. 14 : Pis'ma. 1828 - 1832. - M.: TERRA, 1998. - S. $291-292$.

14. Pushkin A. S. Pis'mo P. V. Nashchokinu ot 29 iyulya 1831 goda // Pushkin A.S. Sobranie sochinenii: V 15 t. T. 14 : Pis'ma. 1828 - 1832. - M.: TERRA, 1998. - S. 279. 
DOI: $10.7256 / 1811-9018.2015 .9 .14629$

При цитировании этой статьи сноска на dоі обязательна

Правовая и политическая мысль

15. Pushkin A. S. Poltava // Pushkin A. S. Sobranie sochinenii: V 15 t. T. 5: Poemy; Iz rannikh redaktsii; Pesni i skazki, sobrannye i zapisannye Pushkinym. - M.: TERRA, 1998. - S. $188-234$.

16. Sosenkov F. S. Voprosy obespecheniya territorial'noi tselostnosti Rossii v politiko-pravovykh vozzreniyakh dekabristov // Vestnik Volzhskoi gosudarstvennoi akademii vodnogo transporta. - 2014. Vypusk 38. - S. 15 - 28.

17. Khairullin V. I. Spravedlivoe obshchestvo ili «utopizm» Dostoevskogo // Gosudarstvo i pravo. - 2004. - №8. - S. 100 - 105. 